\title{
O saber-corpo e a busca pela descolonização da saúde coletiva
}

\author{
The body-knowledge and the search for the decolonization of public \\ health
}

Flavia de Assis Souza1

DOI: 10.1590/0103-11042019S814

RESUMO Pensar o campo da saúde coletiva a partir do corpo que circula nas instituições acadêmicas e nos serviços de saúde proporciona um olhar privilegiado sobre as questões que permeiam tanto a produção do conhecimento quanto os diversos tipos de violências perpetradas pelo sistema. Este ensaio, portanto aponta que o caminho da descolonização da saúde coletiva se mostra como alternativa para que as desigualdades em saúde sejam finalmente desveladas e superadas no âmbito do desenho das políticas de saúde e do Sistema Único de Saúde (SUS).

PALAVRAS-CHAVE Sistema Único de Saúde. Colonialismo. Saúde coletiva.

\begin{abstract}
Thinking about the field of collective health from the perspective of the body that circulates in academic institutions and health services provides us with a privileged look at the issues that permeate both the production of knowledge and the various types of violence perpetrated by the system. Therefore, this essay points out that the path of decolonization of public health is an alternative for health inequalities to finally be unveiled and overcome within the Unified Health System (SUS).
\end{abstract}

KEYWORDS Unified Health System. Colonialism. Public health. 


\section{Refletindo a partir do Saber-corpo}

Meu corpo é o meu território.

(Sandra Benites).

A epígrafe que inicia o presente ensaio chegou como um disparo aos meus ouvidos. Em uma mesa composta por um Babalorixá, um cineasta negro, uma jovem negra e uma mulher indígena, frases como essa têm o poder de nos arrebatar. Esse cenário foi organizado pelo professor Renato Noguera e tratou-se de uma jornada sobre infâncias, raças e etnias e suas interseções, que aconteceu na Universidade Federal Rural no Rio de Janeiro, em julho do corrente ano, no campus de Nova Iguaçu. Descrevo o cenário em detalhes porque é muito potente o diálogo produzido por personagens tão distintos, mas que em certa medida se conectam. E esse encontro aconteceu em uma localidade fora daquilo que podemos chamar de 'eixo geopolítico de produção de conhecimento'. Em outras palavras, essa discussão acontece em um local em que tipicamente esse tipo de debate ocorre muito raramente.

Fiquei durante alguns dias pensando sobre a frase dita por Sandra Benites naquela mesa porque era algo sobre o qual eu mesma já estava refletindo e escrevendo em minha tese de doutorado e é uma temática que me acompanhou durante toda minha trajetória dentro do campo da saúde coletiva. Sandra é uma mulher pertencente à etnia Guarani, antropóloga e educadora, que trabalhou durante muitos anos com educação infantil em aldeias indígenas. Em suma, a sua fala potente enfatizava a importância do não apagamento dos corpos do sujeito indígena no espaço escolar. Para Sandra, os educadores deveriam ouvir os alunos indígenas de modo a construírem em conjunto um saber que respeitasse a cultura e a cosmovisão daqueles sujeitos que deveriam ser envolvidos no processo educacional. Todavia, a antropóloga nos chamava a atenção para o embranquecimento que se impunha aos povos indígenas desde a colonização e que por conta disso a educação brasileira se mantinha colonizadora.

Da mesma maneira, o meu corpo de mulher negra, mãe, nascida na Baixada fluminense, filha de empregada doméstica, durante muitos anos foi desqualificado como um corpo 'apto' a produzir conhecimento dentro da academia. O caráter racista e sexista intrínseco à saúde coletiva fica muito evidente quando uma estudante do doutorado entra no curso com o desejo de estudar um tema a partir do seu corpo marcado pelas diversas estruturas de opressão e esse desejo é violentamente rechaçado. Ocupar o espaço que foi construído pelo homem branco, sendo uma mulher negra, somente lhe é oferecido duas opções: ou você embranquece e se encaixa no modelo de produção de conhecimento instituído ou você desiste do curso. Nós mulheres negras, não temos muitas escolhas em um ambiente extremamente elitista, racista e sexista.

Por conseguinte, fazendo um paralelo com a importante fala de Sandra, também sigo o entendimento de que o corpo precisa ser ouvido, não somente no que tange ao desenho de políticas públicas, mas também na produção de conhecimento. Isso implica entendermos que é no corpo do indivíduo que está inscrito toda a sua ancestralidade, seu modo de ser, as marcas de diversas estruturas de opressão que lhe atravessa, assim como a sua maneira de entender o mundo. É a partir disso que faço algumas reflexões sobre o que aqui estou chamando de saber-corpo e sua contribuição na produção de conhecimento para o campo da saúde coletiva.

Sabemos que o modelo de produção do conhecimento científico moderno ocidental adota o paradigma cartesiano que centra a produção legítima do conhecimento na mente do homem. Ademais, aqui o sentido da palavra que utilizo para a palavra 'homem' não é o de humanidade, mas sim, daquilo que entendemos como 'macho'. Contudo, é importante nos atentarmos para o fato de que esse conhecimento centrado na mente do macho também 
não é de qualquer macho, mas é o conhecimento centrado na mente do macho branco ocidental. Isto é, o conhecimento percebido como legítimo é o produzido a partir da mente do macho-branco-europeu. Com isso, a filosofia e a sociologia ocidental, ao separar o corpo da mente apagaram o sujeito de enunciação e a localização de onde está se produzindo o conhecimento. Com o apagamento do corpo transmite-se a falsa ideia de que o conhecimento científico está isento das subjetividades e da localização desse sujeito nas hierarquias de poder, é a dita imparcialidade da ciência. No entanto, na verdade, essa falsa imparcialidade está impregnada de valores e crenças que são construídas a partir de um ponto de vista. Como afirma Donna Haraway',

as hierarquias de classe, sexuais, de gênero, espirituais, linguísticas, geográficas e raciais desse mundo patriarcal-capitalista-colonial-moderno são inescapáveis.

$\mathrm{Na}$ minha perspectiva, o saber-corpo também pode ser traduzido como o conhecimento produzido a partir da experiência porque coaduna com a ideia de se localizar e de falar a partir das marcas, do espírito e da ancestralidade (inscrita no corpo). Entretanto, acrescento que o saber-corpo não implica abandonar a mente como locus de produção de saberes, mas, trata-se de agregar a este, o corpo e o espírito, formando uma tríade interconectada. Por isso, minha proposta é de tomarmos o corpo de volta ao processo de produção de saberes na academia, o que considero como um necessário ato de rebeldia contra a ciência moderna colonizadora.

Somente dessa maneira, acredito que cosmologias outras, fora da racionalidade patriarcal-branca-europeia, serão entendidas como saberes legítimos. Os autores e autoras negras da diáspora africana e do sul global, têm nos chamado a atenção para o saber ancorado na experiência de homens e mulheres negras.

Dessa forma, bell hooks² aponta para a dificuldade de falar de questões pelas quais o seu corpo encontra-se distanciado. Ao relatar sua experiência como aluna na graduação a autora ressalta que preferia ter estudado o pensamento crítico afro-americano com um professor negro progressista do que com a professora branca com quem fez o curso. É certo que com o professor negro progressista a experiência do corpo negro traria para a sala de aula tanto o saber experimental quanto o saber analítico, o que tornaria o aprendizado da citada disciplina mais enriquecedora. Assim hooks ${ }^{\text {2(123-124) }}$ assinala que

esse ponto de vista [do corpo negro] não pode ser adquirido por meio dos livros, tampouco pela observação distanciada e pelo estudo de uma determinada realidade.

A autora acrescenta: "para mim esse ponto de vista privilegiado não nasce da 'autoridade da experiência', mas sim, da paixão da experiência, da paixão da lembrança"2(123-124). O que podemos constatar no dia a dia do 'fazer ciência' na academia é que o distanciamento do corpo da realidade a ser descrita ou teorizada incorre na formulação de reflexões e opiniões muitas vezes preconceituosas ou distorcidas de determinada realidade.

Ainda refletindo sobre o que bell hooks ${ }^{2}$ chama de 'paixão da experiência' a conotação dessa expressão criada pela a autora nos ajuda a pensar o quanto é importante, digamos, 'colocarmos o corpo para jogo'. A autora traz para a discussão outro nível de entendimento sobre a produção de saberes. À vista disso, hooks ${ }^{2}$ traz a dimensão do sofrimento inscrito no corpo de quem fala como um componente primordial para a construção do conhecimento. Nas palavras da autora:

[a paixão da experiência] é um modo de conhecer que muitas vezes se expressa por meio do corpo, o que ele conhece, o que foi profundamente inscrito nele pela experiência. Essa complexidade da experiência dificilmente poderá ser declarada e definida à distância. É uma posição privilegiada, embora não seja a 
única nem, muitas vezes, a mais importante a partir da qual o conhecimento é possíve|2(124)

Diante do exposto até aqui podemos concluir que o conhecimento produzido a partir da experiência, como reivindicado pelas autoras negras, traz de volta o corpo (como locus privilegiado da produção do conhecimento) para o interior da torre de marfim... a academia.

Em nome do conhecimento imparcial ou da verdade científica diversas vezes corpos brancos teorizando sobre realidades vividas por corpos negros distorcem ou produzem as tais 'zonas cinzentas'. A zona cinzenta é aquilo que fica invisibilizado e que somente é possível de enxergar por meio da paixão da experiência de bell hooks².

É o que acontece no meu curso de PósGraduação em Saúde Coletiva. Não temos professor negro lecionando em nenhuma das três subáreas que compõem o curso. A pós é composta pelas áreas de epidemiologia, política, planejamento e administração em saúde e pelo Departamento de Ciências Humanas. Duas questões se impõem diante dessa constatação. A primeira é: por que que os corpos negros não ocupam o espaço legitimado de produção de conhecimento em um programa de pós-graduação tão importante? $\mathrm{E}$ a segunda é a que já mencionei, por conta dos corpos brancos que dominam esse espaço o debate racial na saúde está ausente ou quando se apresenta é em um formato de 'recorte' e não como ponto central do debate, além de perspectivas muito distanciadas da realidade. Acrescentaria ainda mais um ponto que é a problemática que se instaura, em termos de desenho de políticas públicas, quando o corpo que está pensando as políticas de saúde é o corpo branco cis-heterossexual.

Em vista dos argumentos apresentados, parto do princípio de que o corpo é fonte de produção de saberes, pois carrega a ancestralidade, a visão de mundo e as marcas de inúmeras estruturas de opressão que se incidem sobre ele. $O$ presente ensaio visibiliza o debate sobre três questões interligadas. A primeira é sobre a criação de corpos ideais arquitetada pelo homem branco desde os tempos coloniais, em outras palavras, como corpos brancos cis-heterossexuais se transformaram na norma, ou no corpo 'ideal'. O segundo aspecto discutido é o que nos adverte quem tem legitimidade de produzir conhecimento e quem não tem. Já a terceira questão a ser discutida é sobre os corpos considerados fora da norma. Reflito o quanto a existência de um constructo de corpo 'ideal' influencia nas políticas e práticas de saúde coletiva. Em resumo, como esses corpos fora da norma são tratados no Sistema Único de Saúde (SUS)?

\section{O saber-corpo negro deslegitimado na Pós- Graduação em Saúde Coletiva}

Por que tamanha dificuldade de inserirmos o debate racial no interior do campo da saúde coletiva? Por que temos problemas em reconhecer corpos fora da norma no desenho de políticas de saúde e no seu atendimento no âmbito dos serviços? Essas perguntas nos remetem a tentarmos compreender o movimento da normatização e do apagamento dos corpos característico não somente no campo da saúde, mas, também da ciência. Ressalto que este ensaio não se propõe a chegar em respostas fechadas a respeito das questões levantadas, mas, sim, suscitar um debate até então ignorado pelo campo da saúde coletiva.

Assim, chamo a atenção para o fato de que existe uma ideologia racial que foi introjetada na sociedade brasileira pelo projeto colonial moderno e que cristalizou no nosso 'inconsciente coletivo' dois elementos fundamentais, a normatização do corpo e a noção de raça superior e inferior.

Como afirma Grosfogue ${ }^{3}$ os primeiros colonizadores que chegaram em terras brasilis trouxeram consigo uma enredada estrutura de poder ampla e vasta que provocou mudanças 
profundas na estrutura social que aqui existia. Segundo o autor, desembarcou dos navios portugueses o homem heterossexual/branco/ patriarcal/cristão/militar/capitalista/europeu.

Lélia Gonzalez ${ }^{4}$ sublinha que no século XIX o racismo constituía a ciência da superioridade euro-cristã (branca e patriarcal), na medida em que se estruturava o modelo ariano de explicação que viria a ser não só o referencial das classificações triádicas do evolucionismo positivista das nascentes ciências do homem, como ainda hoje direciona o olhar da produção acadêmica ocidental.

O importante com toda essa história é entendermos que essa estrutura de poder - estabelecida pelo colonialismo - que aqui instaurou-se levou à formação patriarcal, racista, sexista e heteronormativa da sociedade brasileira. Isto é, o corpo branco cis-heterossexual foi normatizado.

Em termos institucionais, de maneira a sustentar e a reproduzir a estrutura patriarcal, racista, sexista e heteronormativa da nossa sociedade, entendo que as universidades tiveram papel essencial. De acordo com José Jorge Carvalho 5 a condição de criação mesma das nossas universidades foi colonizada. Nossa elite branca trouxe uma elite acadêmica europeia branca para fundar uma universidade estritamente nos moldes das universidades ocidentais modernas. O modelo institucional foi o humboltiano, com a separação entre a faculdade e o instituto de pesquisa, obedecendo à mesma divisão de saberes da matriz europeia e inscrevendo nossa academia como uma variante da chamada civilização ocidental.

José Jorge ${ }^{5}$ assinala que o mito racista e xenófobo, resultado dos imperialismos, colonialismos e da escravidão atlântica foi transplantado para o Brasil na criação das nossas universidades. A nossa primeira universidade somente foi inaugurada na segunda década do século XX, a Universidade Federal do Rio de Janeiro (UFRJ) criada por meio de uma missão francesa, instalando assim a nossa elite branca acadêmica como uma continuação da elite acadêmica europeia. $\mathrm{O}$ autor afirma que não sobra observar que nossa colonização mental foi ainda mais completa porque o espaço social no qual as universidades se instalaram era inteiramente branco, o que facilitou a identificação dos nossos acadêmicos com os seus pares (brancos) europeus ${ }^{5(85)}$.

Tendo em vista a hegemonia de corpos brancos dentro das universidades brasileiras, a saúde coletiva resiste firmemente em entender que o racismo é o elemento fundacional do Estado moderno brasileiro. A Pós-Graduação em Saúde Coletiva, pelo menos no meu curso, continua a ignorar que no início do século $\mathrm{XX}$ a política eugenista implementada no Brasil andava de mãos dadas com o sanitarismo. Em sua dissertação de mestrado Vanderlei Sebastião ${ }^{6}$ ressalta que a política eugenista introduzida no Brasil durante os anos de 1910 foi rapidamente difundida como símbolo de modernidade cultural, vista como uma ferramenta fundamental para auxiliar o processo de reforma da saúde pública e de regeneração racial da população. $\mathrm{O}$ autor ainda enfatiza a importante participação do principal teórico eugenista brasileiro, o médico Renato Kehl. Nas palavras de Sebastião6(16):

[...] apesar de Kehl ter participado do movimento sanitarista e defendido por vários anos um programa eugênico mais 'suave', ao estilo da 'eugenia preventiva', no final dos anos 1920 suas ideias foram profundamente reconfiguradas, o que o aproximou dos pressupostos mais radicais oriundos da 'eugenia negativa' alemã, norte-americana e inglesa.

Por isso ressalto a importância de trazermos o debate racial para dentro do campo da saúde. Reconhecer que a ideia de um corpo ideal foi construída pelo colonialismo e que a universidade sustenta esse ideal é imprescindível para que avancemos na direção de uma academia mais inclusiva e de um sistema de saúde que acolha todos os tipos de corpos que por ali circulem. Com relação à problemática do não reconhecimento de corpos fora da norma no 
ambiente dos serviços de saúde, abordarei sobre isso na próxima seção.

A partir daqui evoco uma narrativa que esmiúça, expõe e teoriza sobre parte da minha trajetória acadêmica, pois, acredito que minha história pessoal explicita o processo de deslegitimação sobre determinado saber-corpo, sobretudo aqueles fora do ideal de corpo produzido nas sociedades colonizadas.

Trago novamente bell hooks 7 para essa conversa porque as intelectuais negras têm nos ensinado o quanto é rica a produção de saberes a partir daquilo que a professora Ângela Figueiredo ${ }^{8}$ denomina de 'teorização do cotidiano'. O texto de bell hooks ${ }^{7}$ me fez rememorar a angústia que senti ao defrontar-me com a possibilidade de desenvolver uma pesquisa de tese sobre maternidade a partir da minha própria experiência como mãe. Ao olhar para minha trajetória como estudante de doutorado, percebi que desde o primeiro momento tentei me furtar de desenvolver um trabalho que incluísse aspectos subjetivos em seu desenvolvimento. O campo da saúde coletiva sempre demonstrou, a meu ver, forte resistência a produções com a fala 'em primeira pessoa', privilegiando um apagamento da subjetividade autoral e do seu lugar no mundo.

Durante algum tempo vivi a ambiguidade, pois, ao mesmo tempo que trazia o desejo de escrever algo a partir de minhas reflexões, ou mais autoral, a todo momento era tolhida pelos próprios sentimentos esculpidos na lógica profundamente positivista eurocentrado do campo de conhecimento no qual estou inserida. A minha autorrecusa quanto à possibilidade de desenvolver uma escrita reflexiva, decerto, que era o reflexo de anos de castração intelectual. Por isso, entendi muito bem o drama descrito por bell hooks ${ }^{7(472)}$ quando afirma que:

[...] escrevendo ensaios que incluem reflexões confessionais senti-me, a princípio, insegura a respeito de se eles falariam a um público além de mim mesma e meus amigos. Quando publiquei minha primeira coletânea de ensaios Talking Back (Retrucando), surpreendi-me com as muitas cartas que recebi de negras, discutindo o ensaio, sobre as dificuldades que enfrentei como estudante universitária.

Trouxe comigo essa mesma dúvida a respeito da aceitação do meu trabalho como algo com expressão acadêmica e não meramente um texto que agradaria apenas aos meus companheiros fiduciários daquilo que denomino de epistemologia da resistência. Diante disso, também havia o temor de produzir um estudo com a ideia de repensar o positivismo científico intrínseco à saúde coletiva, mas que ao tentar fazer isso acabasse reproduzindo as mesmas bases científicas que eu mesma estava criticando.

Por conseguinte, refleti sobre o quanto colegas (sobretudo as mulheres negras) da pós-graduação poderiam estar vivendo o mesmo dilema. Ainda discutindo com base no trabalho de hooks ${ }^{7}$, a autora relata a dificuldade das mulheres negras de se inserirem no campo acadêmico. Um dos motivos que mais chamam a atenção no texto é o fato de que mulheres negras desde muito novas são convencidas a não se enxergarem como potenciais formuladoras de saberes. Essas mulheres recebem um tipo de socialização sexista e racista, em que são condicionadas a entender que devem estar sempre prontas para servir a alguém e não para a reflexão.

Outra questão importante, apontada pela autora, é o fato de a escrita das mulheres negras ser muito discriminada. Por conta de se basearem amplamente em suas experiências pessoais, os trabalhos produzidos pelas autoras negras ainda são colocados à prova ou postos em dúvida pela academia. Segundo hooks ${ }^{7}$, isso faz com que essas escritoras assumam o posicionamento do anti-intelectualismo.

À questão do descrédito relacionado com o trabalho produzido pelas intelectuais negras, Patricia Hill Collins? nos ensina que, uma vez que os homens brancos controlam as estruturas de validação do conhecimento ocidental, seus interesses permeiam temas, paradigmas e epistemologias do trabalho acadêmico tradicional. Dessa forma, as experiências das 
mulheres negras africanas, americanas, latino-americanas ou mulheres negras da diáspora têm sido desqualificadas ou até mesmo excluídas daquilo que os acadêmicos chamam de 'conhecimento'.

Por isso, compreendi o porquê de minha inquietação ao confrontar-me com a possibilidade de produzir um saber que, dentro dos parâmetros da ciência positivista eurocentrada, não se encaixava como 'conhecimento científico'. Encontrei nos textos de intelectuais negras como bell hooks, Patricia Hill Collins, Lélia Gonzalez, Sueli Carneiro explicações sobre o silenciamento e apagamento dos saberes das mulheres negras que historicamente foram rechaçadas dos espaços de produção do conhecimento. Precisamos ter em mente que são os homens brancos que dominam o campo do conhecimento, por isso, colocam a ciência a serviço de seus próprios interesses, como apontado por Patricia Hill Collins ${ }^{9}$. Aliás, é importante sempre nos lembrarmos que esses interesses são aqueles ligados à perpetuação do próprio sistema eurocêntrico-branco-racista-classista que sustenta a academia. Ou seja, é a imposição de uma geopolítica do conhecimento que estabelece as relações entre o centro e a periferia do sistema mundo na produção dos saberes. Então, dito de outra maneira, trata-se de quem tem a permissão de produzir o conhecimento e de quem não tem.

Por isso, dentro da geopolítica do conhecimento ou desse sistema eurocêntrico-branco-racista-classista, as mulheres negras têm encarado historicamente a realidade de ter o seu 'fazer ciência' subjugado ou não reconhecido. Durante os dois primeiros anos da pós-graduação tive que lidar com essa realidade. Ao me posicionar quanto ao encaminhamento teórico da minha pesquisa (totalmente ancorado no feminismo negro) deparei-me com um tipo de violência que, até então ignorava: $o$ epistemicídio. Como toda violência praticada por alguém que temos grande apreço e admiração, o epistemicídio se torna difícil de ser detectado por quem é a vítima. O processo de apagamento se dá de maneira muito insidiosa, dissimulada, envolvida por palavras jocosas e até mesmo 'afetuosas'. O mais assustador é que a deslegitimação e a desqualificação é praticada periodicamente, então, a vítima acaba acreditando que de fato aquele meio compartilhado por pessoas 'altamente qualificadas' não lhe pertence.

Sueli Carneiro ${ }^{10(97)}$ define muito bem como se processa o epistemicídio e seus efeitos. Segundo a autora,

O epistemicídio é, para além da anulação e desqualificação do conhecimento dos povos subjugados, um processo persistente de produção da indigência cultural: pela negação ao acesso à educação, sobretudo de qualidade; pela produção da inferiorização intelectual; pelos diferentes mecanismos de deslegitimação do negro como portador e produtor de conhecimento e de rebaixamento da capacidade cognitiva pela carência material e/ou pelo comprometimento da autoestima pelos processos de discriminação correntes no processo educativo.

Assim, a interiorização de uma ideia cuidadosamente construída pelo cânone da ciência branca europeia, ou seja, de que o conhecimento só é válido se for produzido apoiado em parâmetros (brancos) e regras predeterminadas, desmotiva quem não se enquadra nesse perfil. Algumas de nós, intelectuais negras, ao nos utilizarmos de outras cosmologias para entendermos/lermos o mundo, somos imediatamente desqualificadas e banidas do campo acadêmico por não nos encaixarmos nos parâmetros instituídos pela ciência branca. É preciso ressaltar que em nome de sua autopreservação o cânone branco ocidental assume esse posicionamento sob a justificativa de garantir uma suposta imparcialidade e objetividade nos resultados a serem obtidos pelos estudos produzidos na academia.

Desse modo, narro sobre minha própria experiência como mulher, mãe, preta, periférica e acadêmica. A intenção é de alguma maneira visibilizar a violência provocada pela 
branquitude acadêmica em corpos tão marcados quanto o meu; os corpos fora da norma.

O meu corpo atravessado por tantos marcadores da diferença me coloca no lugar do infans, como nos alerta Lélia Gonzalez"11. Ao descrever a localização dos negros na sociedade brasileira - o lugar do subalterno, a autora assinala que, devido a esse lugar, o povo negro é constantemente infantilizado. A autora assinala que infans significa aquele que não tem fala própria, é a criança que se fala na terceira pessoa, porque é falada pelos adultos. Então, para a academia eurocentrada-patriarcal-branca, o meu corpo de mulher negra, periférica e vinda das classes subalternizadas é entendido como aquele incapaz de produzir conhecimento por si; e, por isso, a produção de saberes deve ser referendada por aqueles que são reconhecidos como detentores do legítimo saber, ou, o homem branco. Ou aqueles que desempenham a função de reprodutores da lógica colonizadora.

Dentro dessa academia racista o corpo preto é o corpo fora da norma, pois, como já dito, esse espaço foi pensado e criado pelos e para os corpos brancos. Então, diante da insubmissão do meu corpo preto fui destinada a ser castigada e a sofrer as dores da violência epistêmica. Ainda durante o período pré-qualificação me recordo que demorei muitos dias para escrever aquilo que seria as primeiras páginas do meu projeto de tese. Ao fim de longas semanas consegui o resultado de 84 páginas escritas do projeto de qualificação. Enviei as 84 laudas assim que terminei de escrever ao orientador, entretanto, ele somente leu após três meses. E, logo após a leitura ele desconsiderou a maior parte do que eu havia escrito. Ou seja, passei noites a fio escrevendo para no fim nada do que havia escrito fosse aproveitado; e a justificativa para tal ato era que a minha formação de base havia sido deficitária e que eu precisaria estudar mais. Sem falar nas ocasiões em que expressava minha opinião durante a aula ou no grupo de orientação e tinha minha fala imediatamente desqualificada e diminuída. Nenhuma autora negra que lia e usava para escrever meus textos era considerada boa pelo 'deus da orientação'. Esse mesmo deus se utilizava de seu lugar de poder e autoridade para humilhar e deixar muito claro que o meu corpo preto não tinha legitimidade para produzir por si mesmo nada que pudesse ser considerado como conhecimento. O conhecimento que eu deveria produzir era sempre orientado e tutelado, sempre em direção à Europa.

A academia, mais especificamente, a pós-graduação, tem sido um espaço de adoecimento coletivo, sobretudo para o povo negro. Adoecemos quando, ainda no processo seletivo, nos são impostas inúmeras barreiras que impedem o nosso acesso. Adoecemos quando queremos realizar um trabalho de pesquisa de acordo com nossas experiências e somos tolhidos. Adoecemos quando temos que embranquecer para sermos aceitos.

\section{O mito da neutralidade científica subjacente à saúde coletiva: entrave para políticas emancipatórias}

Donna Haraway discute a questão da "objetividade"/imparcialidade para a ciência e como estes se tornam conceitos totalmente vazios de sentido quando estamos falando da pesquisa feminista. A autora menciona que as feministas têm empreendido muito esforço em criticar o termo e em explicar o seu significado para as suas pesquisas. Para a autora "o saber é policiado por filósofos que codificam as leis canônicas do conhecimento" e na opinião de Haraway', são eles, um grupo pequeno de cientistas masculinistas que têm o poder de ditar as regras da pesquisa acadêmica.

A pretensa imparcialidade ou objetividade do cânone científico, de acordo com a autora, não é nada menos do que uma visão parcializada do fenômeno, é a visão do dominador ou a perspectiva do homem branco europeu. É a imparcialidade do sujeito que se entende como universal. Ou seja, para que a visão de 
mundo do homem branco europeu se torne hegemônica, cria-se o mito de que o conhecimento somente é possível de ser construído a partir da objetividade científica e, para isso, nega-se o lugar de fala dos indivíduos pesquisados, ou lhe é negada a prerrogativa de sujeito potencialmente capaz de produzir conhecimento. Por outro lado, ao darmos voz e ouvidos aos silenciados, como reivindicado por Donna Haraway', há a manifestação de um conhecimento capaz de evidenciar "situações extraordinárias", isto é, que nos leva ao conhecimento não regular, ou àquele que está fora do estabelecido pelo cânone científico. Em outras palavras, segundo a autora,

precisamos também buscar a perspectiva daqueles pontos de vista, que nunca podem ser conhecidos de antemão, que prometam alguma coisa extraordinária, isto é, conhecimento potente para construção de mundos menos organizados por eixos de dominação'.

É interessante também a defesa que a autora faz da versão corporificada da objetividade. Esta é uma perspectiva contrária àquela verdade científica sem corpo e dita imparcial. Donna Haraway ${ }^{1}$ defende a "objetividade corporificada”. Ou seja, esta é uma perspectiva que leva em consideração os corpos marcados, com seus saberes (que são localizados), culturas e trajetórias.

A autora insiste na importância de localizar os saberes, em que políticas e epistemologias de alocação, posicionamento e situação nas quais parcialidade e não universalidade é a condição de ser ouvido. A defesa é por uma visão do saber-corpo, que não é neutro, nem distanciado de sua realidade, ao contrário, está organicamente imbricado nessa realidade.

Toda a reflexão trazida por Donna Haraway ${ }^{1}$ nos fornece instrumentos para entendermos que o saber além de localizado é corporificado. Desse modo, mais uma vez, advogo por uma ciência pensada a partir do corpo. É preciso compreender que o corpo é marcado e atravessado por marcadores sociais da diferença como gênero, raça, classe, sexualidade, território, nacionalidade etc. Esse corpo é capaz de elaborar sua própria epistemologia e de se localizar dentro da hierarquia social, assim como identificar relações de poder. Portanto, cabe a nós pesquisadoras(es) abandonarmos a ideia de objetificá-lo como se ele fosse coisa, e assim, silenciá-lo. Por conseguinte, uma alternativa é a epistemologia feminista negra decolonial, pois tem nos ensinado a fazer ciência baseada nas experiências do saber-corpo.

A partir dessas premissas, ao direcionar a reflexão do saber-corpo para a saúde coletiva, é perceptível que o campo caminhou no sentido de criticar a visão objetificada do corpo, no que tange ao campo de pesquisa. $\mathrm{O}$ esquadrinhamento e o retalhamento do corpo praticado pela medicina com o objetivo de transformá-lo em objeto, de modo a entender e controlar o seu funcionamento, já foram criticados por Foucault ${ }^{12}$ em seu trabalho: 'O nascimento da clínica'. Esse texto é tido como obrigatório nos cursos de Pós-Graduação em Saúde Coletiva, e é utilizado para marcar a crítica do campo à medicina que durante séculos objetificou o corpo.

A discussão sobre biopolítica vai aparecer na obra de Foucault no final da década de 1970, em 'Segurança, território, população' e em 'Nascimento da biopolítica'13. A biopolítica, em outras palavras, significa a utilização de técnicas de biopoderes com vistas ao controle de populações. O discurso médico ancorado em um saber científico como instrumento de biopoder atuará diretamente nas subjetividades dos indivíduos, alterando seus valores sobre os modos de viver. Desse modo, a biopolítica se ocupará em gerir a saúde, a alimentação, a natalidade, a sexualidade, impondo assim o disciplinamento dos corpos. Para Daniel Fernandes e Gabriela Resmini14(1):

[biopolítica] Ela representa uma 'grande medicina social' que se aplica a população a fim de controlar a vida: a vida faz parte do campo do poder. $O$ pensamento medicalizado utiliza meios de correção que não são meios de punição, mas meios de transformação dos 
indivíduos, e toda uma tecnologia do comportamento do ser humano está ligada a eles. Permite aplicar a sociedade uma distinção entre o normal e o patológico e impor um sistema de normalização dos comportamentos e das existências, dos trabalhos e dos afetos.

Baseada nas obras citadas a saúde coletiva faz a crítica sobre a normatização dos corpos, entretanto, sem racializá-los; além de não discutirmos o quanto, nós planejadores de políticas de saúde, também temos pensado saúde a partir do corpo normatizado. A normatização dos corpos e seu apagamento produzem efeitos no que concerne às práticas de saúde na medida em que estabelece também a ideia de um corpo universal. Este significa que são ignorados os inúmeros atravessamentos que marcam os corpos dos indivíduos. Marcadores como gênero, raça, classe, geração, sexualidade, ancestralidade entre outros, não são evidenciados na ideia de corpo construída pela branquitude colonizadora, ou seja, o corpo universal é essencialmente branco e cis-heteronormativo.

Por isso, ao pensar em escrever este ensaio, além do desejo de discutir os efeitos do apagamento do meu corpo como locus de produção de conhecimento, fui também muito motivada pela reflexão sobre a possibilidade de existência dos corpos lidos como 'estranhos'. A modernidade colonial foi bem-sucedida em impor a criação de um 'Outro', ou, aquele que é estranho à norma do corpo branco cis-heterossexual. É importante deixar claro que desde então a violência é exercida sobre esses corpos, que, por sua vez, não enxergam a possibilidade de existência fora desse signo. Assim, esse corpo que não é reconhecido pelo conjunto da sociedade, pois está fora da norma, ao circular pelo sistema de saúde sofre o estigma da violência. Seja a violência física como a obstétrica, preponderante sobre os corpos das mulheres negras, seja a violência psíquica perpetrada pelos próprios trabalhadores da saúde diante de outros corpos tidos como fora da norma (população LGBTQI+).
Na minha perspectiva, o movimento de Reforma Sanitária, por ter sido idealizado e liderado, em sua grande maioria, por homens brancos oriundos da classe média, que predominantemente eram médicos do sistema, ou professores de universidades pode ter influenciado um espelhamento da branquitude e da heteronormatividade na construção do SUS. Dessa maneira, o movimento de Reforma Sanitária não discutiu o direito à saúde a partir da perspectiva de saberes e corpos colonizados racializados, e, por esse motivo, utilizou-se da ideia do corpo universal. O indicativo disso é o fato de que o Programa Nacional de Saúde Integral da População Negra (PNSIPN) somente foi criado no ano de 2009 . O reconhecimento de que havia (e ainda há) uma desigualdade brutal quanto ao acesso e à discriminação nas práticas de saúde para com o povo negro somente aconteceu após 21 anos de instituição do SUS. No entanto, é importante ressaltar que o reconhecimento da iniquidade no setor saúde ocorre somente no âmbito legal, pois poucas mudanças são observadas no cotidiano dos serviços no que se refere ao combate à discriminação racial.

Jurema Werneck ${ }^{\mathbf{1 5}}$ em seu artigo 'Racismo institucional e saúde da população negra' demonstra a ausência de estudos sobre a saúde da mulher no campo da saúde coletiva. Em uma pesquisa preliminar a autora revela que a pesquisa com o descritor 'saúde da mulher negra' obteve apenas seis artigos. Assim, Werneck levanta o questionamento sobre o porquê dessa ausência/insuficiência de pesquisas que versem sobre a temática racial na saúde. A autora ressalta que não há como sabermos ao certo a origem dessa problemática, mas levanta algumas hipóteses, tais como: desinteresse, falta de estímulo ou existência de restrições explícitas nas instituições de pesquisas, barreiras interpostas pelos conselhos editoriais dos diferentes periódicos, ou a combinação de todos esses elementos. Todavia, o que de mais importante concluímos com o apontamento da autora é que essa ausência de artigos da citada temática significa a não consolidação da saúde 
da população negra e da saúde da mulher negra como campos de pesquisa, o que está relacionado com o baixo grau de penetração nas instituições de pesquisa dos debates sobre o racismo, seus impactos na saúde e suas formas de enfrentamento.

$\mathrm{O}$ artigo de Jurema Werneck ${ }^{15}$ dialoga sobremaneira com o presente ensaio, pois, assim como a autora, identifiquei a ausência do debate racial no interior da Pós-Graduação em Saúde Coletiva e consequentemente, o apagamento do corpo negro. Outrossim, esse apagamento ocorreu inclusive no movimento de Reforma sanitária que teve início no final da década de 1970 . Werneck corrobora meu posicionamento de que o debate racial esteve ausente no movimento que instituiu o SUS. A autora sublinha que o movimento negro, sobretudo o de mulheres negras esteve presente nos processos de Reforma Sanitária e de instituição do SUS. A autora ressalta que a presença do movimento negro contribuiu para a concepção de um sistema universal de saúde com integralidade, equidade e participação social, mas não foi suficiente para inserir no novo sistema mecanismos de superação das barreiras enfrentadas pela população negra no acesso à saúde, particularmente aquelas impostas pelo racismo.

Em síntese, entender a garantia do direito à saúde a partir da universalidade, como afirma Deivison Faustino ${ }^{\mathbf{1 6}}$ "entendida nos marcos liberais", a meu ver, trouxe em seu bojo a garantia de políticas pensadas a partir de um corpo igualmente universal.

Logo, ao pensarmos saúde a partir de corpos universais - que é o corpo não marcado pelas diferenças - observamos que há o impacto, tanto no acesso quanto na prática de saúde em si, o que configura um enorme entrave para a consolidação das diretrizes do SUS. Como nos alerta Melo e Gonçalves ${ }^{17}$,

apesar de termos, no âmbito federal, um número significativo de propostas de ações que se fundam na atenção simultânea a discriminações diversas, no mundo concreto das políticas públicas os sujeitos continuam a ser pensados universalmente.
Isso significa dizer que mulheres negras ainda são as maiores vítimas de violência obstétrica, ou, que corpos LGBTQI+ ainda são tratados com grande estranhamento por parte dos profissionais que atendem nos serviços de saúde. Sem falar quando o indivíduo se encontra em uma encruzilhada de múltiplos marcadores sociais da diferença, colocando-o em uma posição de extrema vulnerabilidade. Nessa situação seu atendimento necessitaria de um olhar cuidadoso, por parte dos profissionais de saúde, sobre os efeitos desses múltiplos marcadores. Como afirmam Melo e Gonçalves ${ }^{17(169-170)}$ :

Ainda que no âmbito das políticas governamentais universais haja uma tendência para o reconhecimento de singularidades identitárias - como raça, gênero e geração -, estas em geral não são apreendidas de maneira interseccionada, uma vez que as ações e projetos raramente se destinam a combater, simultaneamente, múltiplas diferenças e desigualdades, concomitantes a formas diversas de discriminação e exclusão sociais.

Pensemos no questionamento dos autores sobre como desenhar políticas no âmbito do SUS de modo que essas visem atender o sujeito, atravessado por múltiplos marcadores sociais da diferença. A meu ver, a questão se coloca como um tema no qual os pensadores do campo da saúde coletiva devem debruçar-se. De acordo com um exemplo de Melo e Gonçalves ${ }^{17}$ :

$$
\begin{aligned}
& \text { imaginemos o caso de como seria o atendi- } \\
& \text { mento numa consulta ao ginecologista a uma } \\
& \text { mulher lésbica. Sabemos que os profissionais } \\
& \text { da saúde não estão habilitados para realizar } \\
& \text { o atendimento a pessoas fora do modelo de } \\
& \text { 'corpo ideal' (branco e cis-heterossexual). }
\end{aligned}
$$

Ou seja, essas mulheres passam pelo constrangimento de ter de responder perguntas sobre gravidez, uso de contraceptivos, aborto e até sobre possíveis dores durante a penetração. 


\section{Rumo à descolonização}

O trabalho de Melo e Gonçalves ${ }^{17}$ é fundamental, pois nos alerta para o fato da necessidade de abandonarmos o ideal do corpo universal. Defendo então a necessidade de uma virada decolonial no pensamento sanitário brasileiro, no que tange ao desenho de políticas de saúde, para que possamos superar as desigualdades arraigadas nesse sistema. Fica claro no texto que a saída apontada pelos autores é por meio de uma perspectiva interseccionada desse sujeito.

A interseccionalidade configura-se como uma perspectiva que pensa o sujeito a partir das múltiplas opressões sofridas. Significa olhá-lo a partir da articulação de múltiplos marcadores sociais da diferença e apreender 'a diferença que faz diferença' diante de um cenário de múltiplas opressões. Apesar da interseccionalidade configurar-se como um proficiente método ou episteme de abordagem sobre determinado problema, no caso de construção de políticas públicas, seria necessária uma abordagem mais ampliada.

Houria Bouteldja ${ }^{18}$ ressalta que ao adotarmos a perspectiva interseccionada para pensarmos agenda política instala-se uma problemática. Por conta do elevado grau de abstração da perspectiva interseccional, é quase impossível determinar uma agenda única para reivindicações políticas. Além disso, a definição de um sujeito revolucionário em uma perspectiva interseccional, ou no qual se constituirá o projeto de transformação social, representará a figura daquele indivíduo que é o mais oprimido dos oprimidos. Além disso, de acordo com a autora, como são minoria, dependeriam daqueles que estão fora do grupo, mas que se solidarizam com a causa, pois, de maneira contrária, não seria suficientemente capaz de provocar tensionamento político.

Ademais, a análise de Houria Bouteldja ${ }^{18}$ nos aponta para a alternativa de que seria mais producente nos organizarmos ao redor do sujeito colonizado racializado no sentido de produzirmos transformações sociais mais profundas. Segundo a autora,

Aquilo que eu gostaria de dizer a todas e todos vocês é que a partir da questão da raça, assumindo tal hierarquia, o pensamento decolonial propõe um relato sobre a totalidade que integra o gênero, a classe, a sexualidade, mas que nos liberta de toda forma de eurocentrismo e trabalha para o desafio radical da modernidade que, por meio do imperialismo, do capitalismo e da constituição dos Estados nação, contribuiu largamente na produção do tríptico raça, classe e gênero18(9).

Notemos que a proposta de Bouteldja ${ }^{18}$ é pensarmos as questões político-sociais com base em uma perspectiva decolonial; e, no que tange à formulação de políticas públicas, centremos no sujeito colonizado racializado. A abordagem decolonial amplia o foco, pois, além de trabalhar a partir da questão da raça, integra outras opressões estruturais próprias ao sujeito colonizado racializado.

Destarte, por que a virada decolonial no pensamento sanitário é importante? Porque, dessa maneira, assumiríamos que o evento da colonização introduziu a ideia de raça como elemento estrutural das relações políticas, econômicas e sociais no País. A partir daí, instaurou a ideologia de raça superior e inferior, estabelecendo o racismo e outras formas de opressão como o modus operandi do Estado, das instituições, das leis e das relações sociais. Tendo o racismo e a cis-heteronormatividade como estruturas que organizam a vida na sociedade brasileira, o sistema de saúde e por consequência, as políticas de saúde não passaram ilesas quanto à ingerência dessa estrutura.

A minha proposta assenta-se, portanto, na emergência de pensarmos políticas e práticas de saúde a partir de um sujeito que passou pelo evento da colonização sob o signo da violência, ou seja, negras/os e indígenas. Isso é importante porque a raça ganha centralidade em nossas elaborações de políticas de saúde, ou seja, a base para pensarmos saúde estaria na raça tendo no horizonte a totalidade do sujeito que integraria questões como gênero e sexualidade. A classe, a meu ver, não se descola da raça, no caso do sujeito colonizado racializado, raça é 
classe, como nos adverte Angela Davis ${ }^{\mathbf{1 9}}$.

O segundo movimento imprescindível no sentido da virada decolonial no campo da saúde coletiva está relacionada com a descolonização dos saberes e corpos. Significa dizer que é necessário imprimir mudanças na formação acadêmica dos pensadores da saúde. Apesar da aguda crítica que o campo da saúde coletiva faz a medicina, a grade curricular dos cursos da pós-graduação ainda é muito branqueada. Temos poucas disciplinas que pautam relações étnico-raciais, isto é, ainda persiste nas grades curriculares disciplinas cujas referências são preponderantemente de autores europeus. Estou dizendo que não se tem discutido, nas disciplinas do curso de Pós-Graduação em Saúde Coletiva, o quanto a raça molda diferentes maneiras de olhar o mundo e o quanto são ricas as reflexões de autoras/es negra/os sobre os efeitos do racismo em seus corpos e mentes. Autores que revolucionaram o pensamento sociológico como: Frantz Fanon, Clovis Moura, Abdias do Nascimento, Lélia Gonzalez, Beatriz do Nascimento, entre muitos outros, que trouxeram o ponto de vista do negro para o interior do pensamento político brasileiro, mas que, infelizmente, ainda não alcançaram as bibliografias do campo da saúde. Estudantes passam pelos cursos de especialização, mestrado e doutorado sem sequer ouvir falar de obras essenciais desses autores. Por outro lado, ninguém sai do curso de Pós-Graduação em Saúde Coletiva sem entrar em contato com textos de autores como: Marx, Foucault e Weber.

Em síntese, trilhar o caminho rumo à descolonização do campo da saúde coletiva e consequentemente, das políticas e práticas em saúde significa repactuar o projeto de nação que foi introjetado pelo colonizador europeu há, pelo menos, 500 anos. Práticas racistas que até os dias de hoje acontecem nos sistemas de saúde são encobertas pelo mito da democracia racial, e precisam urgentemente ser derrubadas.

\section{Colaborador}

Souza FA (0000-0003-2197-8609)* é responsável pela elaboração do manuscrito.

\section{Referências}

1. Haraway D. Saberes localizados: a questão da ciência para o feminismo e o privilégio da perspectiva parcial [internet]. Cad Pagu. 2009 [acesso 2019 maio 20]; (5):7-41. Disponível em: https://periodicos.sbu.unicamp.br/ojs/index.php/cadpagu/article/view/1773.

2. hooks b. Ensinando a transgredir: a educação como prática da liberdade. 2. ed. São Paulo: Martins Fontes; 2017.
3. Grosfoguel R. Para descolonizar os estudos de economia política e os estudos pós-coloniais: transmodernidade, pensamento de fronteira e colonialidade global. In: Santos BS, Meneses MP. Epistemologias do Sul. Coimbra: Almedina; 2009. p. 383-417.

4. Gonzalez L. A categoria político-cultural da Amefricanidade. In: Gonzalez Lélia. Primavera para as
*Orcid (Open Researcher and Contributor ID). 
rosas negras. São Paulo: Diáspora Africana; 2018. p. 321-334.

5. Carvalho JJ. Encontro de Saberes e descolonização: para uma refundação étnica, racial e epistêmica das universidades brasileiras. In: Bernardino-Costa J, Maldonado-Torres N, Grosfoguel R, editores. Decolonialidade e Pensamento Afrodiaspórico. Belo horizonte: Autêntica; 2019. p. 79-106

6. Souza VS. A política biológica como projeto: A "Eugenia negativa” e a construção da nacionalidade na trajetória de Renato Kehl (1917-1932). [dissertação]. Rio de Janeiro: Casa de Oswaldo Cruz, Fundação Oswaldo Cruz; 2006. p. 220.

7. hooks b. Intelectuais Negras [internet]. Estudos Feministas. 1995 [acesso em 2019 maio 20]; 3(2):464478. Disponível em: https://periodicos.ufsc.br/index. php/ref/article/view/16465/15035.

8. Figueiredo A. Somente um ponto de vista [internet]. Cad Pagu. 2017 [acesso em 2019 maio 22]; (51):e175117. Disponível em: http://www. scielo.br/scielo.php?script=sci_arttext\&pid =S0104-83332017000300509.

9. Hill CP. Epistemologia feminista negra. In: Bernardino-Costa J, Maldonado-Torres N, Grosfoguel R, editores. Decolonialidade e pensamento afrodiaspórico. Belo Horizonte: Autêntica; 2019. p. 139-170.

10. Carneiro S. A construção do outro como não-ser como fundamento do ser [tese]. São Paulo: Universidade de São Paulo; 2005.

11. Gonzalez L. Racismo e Sexismo na cultura brasileira. In: Gonzalez L. Primavera para as rosas negras. São Paulo: Diáspora Africana; 2018. p. 190-214.

12. Foucault M. O nascimento da clínica. 7. ed. São Paulo: Forense Universitária; 2013.
13. Foucault M. Nascimento da Biopolítica. São Paulo: Martins Fontes; 2008.

14. Fernandes D, Resmini G. Biopolítica [internet]. [acesso em 2019 set 12]. Disponível em: http://www.ufrgs. br/e-psico/subjetivacao/espaco/biopolitica.html.

15. Werneck J. Racismo Institucional e saúde da população negra. Saúde e Sociedade [internet]. 2016 [acesso em 2019 set 13]; 25(3):535-549. Disponível em: http:// www.scielo.br/pdf/sausoc/v25n3/1984-0470-sausoc-25-03-00535.pdf.

16. Faustino DM. A universalização dos direitos e a promoção da equidade: o caso da saúde da população negra. Ciênc. Saúde Colet. [internet]. 2017 [acesso em 2019 set 14]; 22(12):3831-3840. Disponível em: http://www.scielo.br/pdf/csc/v22n12/1413-8123csc-22-12-3831.pdf.

17. Melo L, Gonçalves E. Diferença e interseccionalidade: notas para pensar práticas em saúde [internet]. RC. 2010 [acesso em 2019 maio 22]; 11(2). Disponível em: https://periodicos.ufrn.br/cronos/article/ view/2157.

18. Bouteldja H. Raça, Classe e Gênero: uma nova divindade de três cabeças [internet]. Cadernos GenDiv. 2016 [acesso em 2019 maio 29]; 2(2):5-9. Disponível em: https://portalseer.ufba.br/index.php/cadgendiv/ article/view/20686

19. Davis A. Mulheres, raça e classe. São Paulo: Boitempo; 2016.

Recebido em 02/06/2019

Aprovado em 03/10/2019

Conflito de interesses: inexistente

Suporte financeiro: não houve 